\title{
Correction to: MeioCapture: an efficient method for staging and isolation of meiocytes in the prophase I sub-stages of meiosis in wheat
}

\author{
Arun S. K. Shunmugam', Venkatesh Bollina', Stefanie Dukowic-Schulze ${ }^{2}$, Pankaj K. Bhowmik', Chris Ambrose ${ }^{3}$, \\ James D. Higgins ${ }^{4}$, Curtis Pozniak ${ }^{5}$, Andrew G. Sharpe ${ }^{1,6}$, Kevin Rozwadowski ${ }^{7}$ and Sateesh Kagale ${ }^{1 *}$
}

\section{Correction to: BMC Plant Biol (2018) 18:293 https://doi.org/10.1186/s12870-018-1514-z}

Following publication of the original article [1], a reader spotted an incorrect citation of the reference 14 [2] in the 'Background'. The male meiocyte isolation work described in this article [2] was carried out in rice and not in Brassica as originally stated in the 'Background' [1]. Thus, the following amendment to the Background section should be noted:

Original sentence:

"Several methods have been previously described or proposed for the isolation of male meiocytes [6], such as micromanipulation (Plumbago [10, 11], Nicotiana [12], Brassica [13, 14], Arabidopsis [15, 16, 17] and sunflower [18]), capillary collection of meiocytes (CCM) (Arabidopsis $[19,20]$ and maize $[21,22])$, laser capture microdissection (LCM) in rice [23, 24, 25, 26], Percoll gradient separation (Arabidopsis [27, 28], rice [29] and Brassica [30]) and isolation of nuclei tagged in specific cell types (INTACT) in Arabidopsis [31]."

Corrected sentence:

"Several methods have been previously described or proposed for the isolation of male meiocytes [6], such as micromanipulation (Plumbago [10, 11], Nicotiana [12], Brassica [13], rice [14], Arabidopsis [15, 16, 17] and sunflower [18]), capillary collection of meiocytes (CCM) (Arabidopsis [19, 20] and maize [21, 22]), laser capture microdissection (LCM) in rice [23, 24, 25, 26], Percoll gradient separation (Arabidopsis [27, 28], rice [29] and Brassica [30]) and isolation of nuclei tagged in specific cell types (INTACT) in Arabidopsis [31].".
Author details

${ }^{1}$ National Research Council Canada, Saskatoon, SK, Canada. ${ }^{2}$ Department of Horticultural Science, University of Minnesota, St. Paul, MN, USA.

${ }^{3}$ Department of Biology, University of Saskatchewan, Saskatoon, SK, Canada. ${ }^{4}$ Department of Genetics and Genome Biology, University of Leicester, Leicester, UK. ${ }^{5}$ Department of Plant Sciences, University of Saskatchewan, Saskatoon, Canada. ${ }^{6}$ Global Institute for Food Security, University of Saskatchewan, Saskatoon, Canada. ${ }^{7}$ Agriculture and Agri-Food Canada, Saskatoon, SK, Canada.

Published online: 02 May 2019

References

1. Shunmugam ASK, Bollina V, Dukowic-Schulze $S$, et al. MeioCapture: an efficient method for staging and isolation of meiocytes in the prophase I sub-stages of meiosis in wheat. BMC Plant Biol. 2018;18(1):293.

2. Collado-Romero M, Alós E, Prieto P. Unravelling the proteomic profile of rice meiocytes during early meiosis. Front Plant Sci. 2014;5.

* Correspondence: Sateesh.Kagale@nrc-cnrc.gc.ca

${ }^{1}$ National Research Council Canada, Saskatoon, SK, Canada

Full list of author information is available at the end of the article

(c) The Author(s). 2019 Open Access This article is distributed under the terms of the Creative Commons Attribution 4.0 International License (http://creativecommons.org/licenses/by/4.0/), which permits unrestricted use, distribution, and reproduction in any medium, provided you give appropriate credit to the original author(s) and the source, provide a link to the Creative Commons license, and indicate if changes were made. The Creative Commons Public Domain Dedication waiver (http://creativecommons.org/publicdomain/zero/1.0/) applies to the data made available in this article, unless otherwise stated. 